\title{
Relative strengths of three linearizations of receptor availability: Saturation, Inhibition, and Occupancy plots
}

\author{
Javad Khodaii ${ }^{1 ; 2}$, Mostafa Araj-Khodaei², Manouchehr S. Vafaee ${ }^{3 ; 4 ; 5}$, \\ Dean F. Wong ${ }^{6}$, Albert Gjedde $3 ; 7 ; 8 ; 9 ; *$
}

1 Amirkabir University of Technology, Department of Mechanical Engineering, Tehran, 1591634311, Iran

2 Tabriz University of Medical Sciences, Aging Research Institute, Physical Medicine and Rehabilitation Research Center, Tabriz, 5166-15731, Iran

3 University of Southern Denmark, Department of Clinical Research, BRIDGE-Brain ResearchInter-Disciplinary Guided Excellence, Odense, 5230, Denmark

4 University of Southern Denmark, Research Unit for Psychiatry Southern Region, Odense, 5230, Denmark

5 Odense University Hospital, Department of Nuclear Medicine, Odense, 5230, Denmark

6 Washington University in St Louis, Mallinckrodt Institute of Radiology, Missouri 63110, USA

7 Aarhus University, Translational Neuropsychiatry Unit, Department of Clinical Medicine, University Park 13, Building 2B, DK-8000 Aarhus C; Denmark

8 University of Copenhagen, Department of Neuroscience, Panum Institute, DK-2200 Copenhagen N, Denmark

9 Tabriz University of Medical Sciences, Neurosciences Research Center (NSRC), Tabriz, 5166-15731, Iran

${ }^{*}$ Corresponding Author: Albert Gjedde, Silkeborgvej 673, 8220 Brabrand, Danmark, +4529177601, email: albert.gjedde@clin.au.dk

First Author: Javad Khodaii (Ph.D.), Amirkabir University of Technology, Department of Mechanical Engineering, Tehran, 1591634311, Iran, +989146110911, Javadkhodaii@gmail.com

Word Count: 5400

Funding: This study was supported by Parkinsonforeningen, Lundbeckfonden (R77-A6970) and Danish Agency for Science and Higher Education.

Short Title: Linearization of receptor availability. 


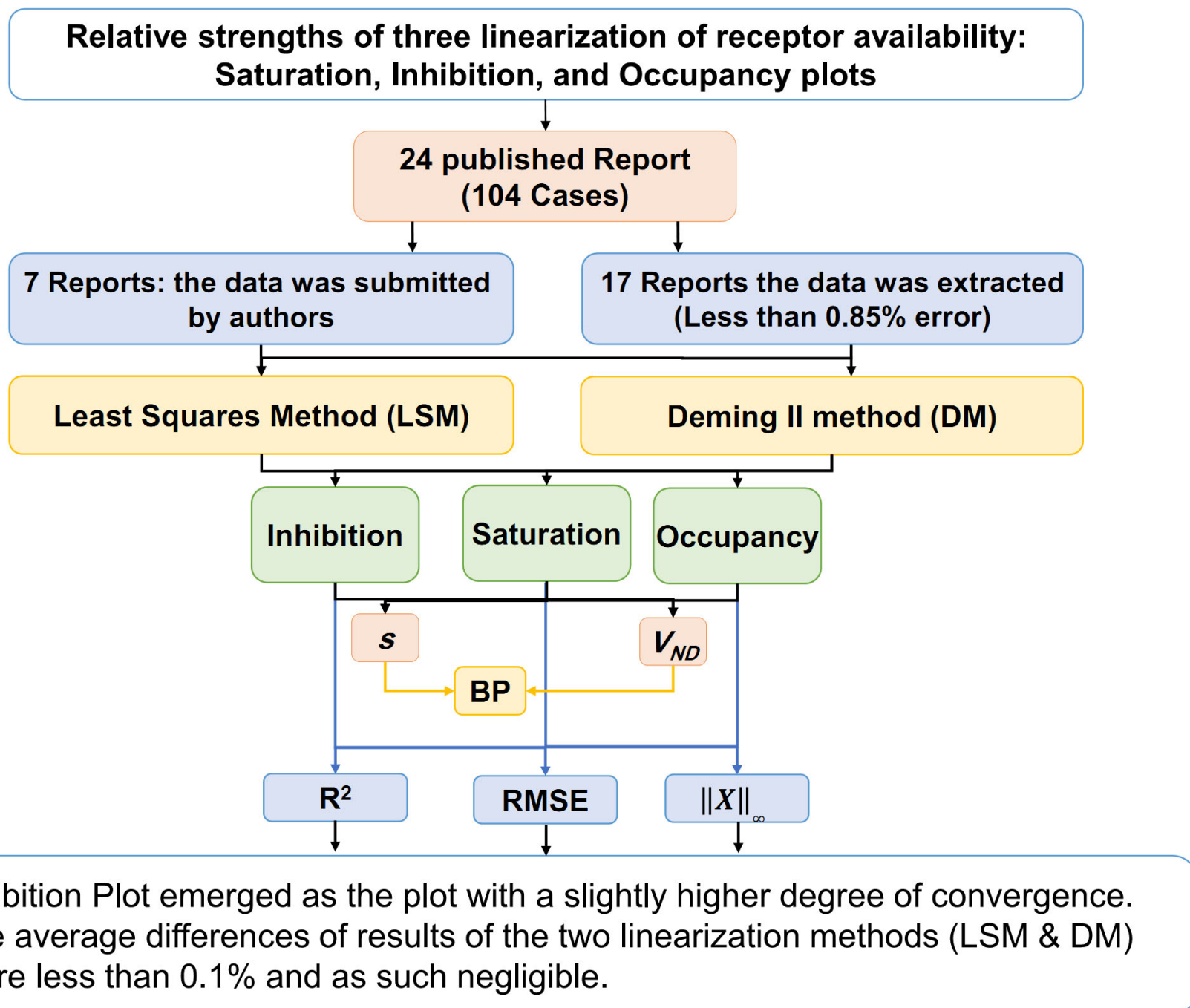

Graphical Abstract 


\section{ABSTRACT}

We derived three widely used linearizations from the definition of receptor availability in molecular imaging with Positron Emission Tomography. The purpose of the present research was to determine the convergence of the results of the three methods in terms of three parameters, occupancy (s), distribution volume of the non-displaceable binding compartment $\left(\mathrm{V}_{\mathrm{ND}}\right)$, and binding potential of the radioligand $\left(\mathrm{BP}_{\mathrm{ND}}\right)$, in the absence of a gold standard. We tested 104 cases culled from the literature and calculated the goodness of fit of each of the Least Squares (LSM) and Deming II (DM) methods of linear regression when applied to the determination of the three main parameters, $s, V_{N D}$, and $B P_{N D}$, using the goodness of fit parameters $\mathrm{R}^{2}$, coefficient of variation (RMSE), and $\|X\|_{\infty}$ with both regression methods. We observed superior convergence among the values of $\mathrm{s}, \mathrm{V}_{\mathrm{ND}}$, and $\mathrm{BP}_{\mathrm{ND}}$ for the Inhibition and Occupancy plots. The Inhibition Plot emerged as the plot with a slightly higher degree of convergence (based on $\mathrm{R}^{2}, \mathrm{RMSE}$ and $\|X\|_{\infty}$ value). With two regression methods, Least Squares (LSM) and Deming II (DM), the estimated values of s, $\mathrm{V}_{\mathrm{ND}}$, and BP $\mathrm{ND}$ generally converged. The Inhibition and Occupancy plots yielded the best fits to the data, according to the goodness of fit parameters, due primarily to the absent commingling of the dependent and independent variables tested with the Saturation (original Lassen) plot. In the presence of noise, the Inhibition and Occupancy plots yielded higher convergence.

Keywords: Positron Emission Tomography, Lassen Plots, Inhibition Plot, Binding Potential INTRODUCTION

Positron Emission Tomography (PET) is a major tool of biomedical research with clinical applications that yields images of the distribution of systemically administered positron- 
emitting radionuclides in tomographic sections of the bodies of human subjects and experimental animals $(1,2)$. Positrons are positively charged anti-electrons emitted from the nuclei of short-lived isotopes typically produced in a cyclotron. Users of this technique image the high energy $(511 \mathrm{KeV})$ annihilation photons that result from the interaction of a positron with electrons in the tissue. PET images are reconstructed by means of computed tomography of the source of radioactivity, following injection of radiopharmaceuticals according to the principles of nuclear medicine (3). The imaging of neuroreceptors with radioactive ligands by PET applied to living mammalian brains makes it possible to determine receptor density and affinity by appropriate mathematical models (4).

Neuroreceptor studies of brain in vivo using PET require comparisons of so-called binding potentials of radiopharmaceutical receptor ligands at more or less inhibited receptor states to obtain estimates of receptor density and affinity (5). Naganawa et al. (6) proposed methods that reduce bias and variability, and the best use of these approaches is realized by improving the accuracy of data covariance matrices.

The quantitative determination of binding potentials uses a fundamental equation of receptor availability to obtain separate estimates of radioligand volumes of distributions of a specific radioligand (5,7-10). Application of any one of the three linearizations presented here is the first step towards the determination of the binding potentials (or receptor availabilities) that is foundation of the receptor binding analysis. In cases where a proper reference region with no specific binding of the ligand is not known to exist, or is known not to exist, three linearized versions of receptor availability equation were derived for the purpose of estimation of the magnitude of $\mathrm{VND}_{\mathrm{ND}}$ by linear regression. The three different plots emerged when the Equation of receptor availability was linearized differently by Lassen et al., Gjedde and Wong, 
and Cunningham et al. (11-13). Here, the three different plots are referred to as the Saturation, Inhibition, and Occupancy Plots, to avoid the uncertain naming of the plots associated with the presentation of the Occupancy Plot solution (12), referred to by some authors as the Lassen Plot rather than the plot that Lassen et al. (11) actually used and reported. The Occupancy and Saturation plots commingle the dependent and independent variables by calculating the difference between the volume estimates for baseline and inhibition states, unlike the Inhibition Plot that simply plots the values of $\mathrm{V}_{\mathrm{T}}$ at inhibition $\left(\mathrm{V}_{\mathrm{T}}(\mathrm{i})\right.$, ordinate) against the values at baseline $\left(\mathrm{V}_{\mathrm{T}(\mathrm{b})}\right.$, abscissa).

The aim of the present research was to determine the accuracy and precision of these three widely used linearization of receptor availability (Saturation Inhibition, and Occupancy plots) from experimental data. We compared 104 cases culled from the literature, the accuracy of each plot evaluated by the Least Squares and Deming II methods of linear regression.

\section{MATERIALS AND METHODS}

The quantitative determination of binding potentials uses a fundamental equation of receptor availability to obtain separate estimates of radioligand volumes of distributions of a specific radioligand $(5,7-10)$ :

$1-s=\frac{V_{T(i)}-V_{N D}}{V_{T(b)}-V_{N D}}$

where Equation (1) is the formulation of the relative or fractional receptor availability in terms of the relevant volumes of distribution. Here, the term $s$ represents the occupancy and the term $V_{T(i)}$ is the apparent total volume of distribution of the sum of the specifically bound and the non-specifically dissolved ligand molecules occupying the receptor, while the term $V_{N D}$ 
refers to the distribution volume of the tracer in a non-binding compartment, also known as the partition volume or partition coefficient of the ligand. The term $V_{T(b)}$ refers to the apparent total volume of distribution of the radioligand in a baseline state where the receptor is not occupied by a specific inhibitor.

Application of any one of the three linearizations presented here is the first step towards the determination of the binding potentials (or receptor availabilities) that is foundation of the receptor binding analysis. Binding potentials $\left(B P_{N D}\right)$ enter into the particular Eadie-Hofstee version of the linearized Michaelis-Menten equation that yields both the maximum binding $\left(B_{\max }\right)$ and the affinity constant (Michaelis half-saturation concentration), $K_{\mathrm{D}}$, of the receptors,

$B=B_{\max }-K_{D} B P_{N D}$

where $B$ is the quantity of bound ligand. The binding potential is defined as the ratio of the volumes of distribution of specifically bound ("displaceable") and non-specifically bound ("nondisplaceable") ligand quantities $(14,15)$. To determine the binding potential of a radioligand, the volumes of distribution are entered into the relationship that defines the binding potential $(2,5,16):$

$B P_{N D}=\frac{V_{T}-V_{N D}}{V_{N D}}$

which is applicable both to the receptor binding baseline and to multiple degrees of receptor blockade, provided the $V_{N D}$ estimate is unaffected by the blockade. To calculate binding potentials, it is necessary to know the distribution of unbound ligand in a region of no binding, but a suitable reference region often does not exist, or is not known to exist.

In cases where a proper reference region with no specific binding of the ligand is not known to exist, or is known not to exist, three linearized versions of Equation (1) were derived 
for the purpose of estimation of the magnitude of $\mathrm{V}_{\mathrm{ND}}$ by linear regression. The three different plots emerged when Equation (1) of fractional receptor availability (1-s) was linearized differently by Lassen et al., Gjedde and Wong, and Cunningham et al. (11-13). Here, the three different plots are referred to as the Saturation, Inhibition, and Occupancy Plots, to avoid the uncertain naming of the plots associated with the presentation of the Occupancy Plot solution (12), referred to by some authors as the Lassen Plot rather than the plot that Lassen et al. (11) actually used and reported. The Occupancy and Saturation plots commingle the dependent and independent variables by calculating the difference between the volume estimates for baseline and inhibition states, unlike the Inhibition Plot that simply plots the values of $\mathrm{V}_{T}$ at inhibition $\left(\mathrm{V}_{T(\mathrm{i})}\right.$, ordinate) against the values at baseline $\left(\mathrm{V}_{T(\mathrm{~b})}\right.$, abscissa).

The three linearizations evaluated here serve to determine a reference volume of distribution of radioligands when no reference region (i.e., a region of absent specific binding) is known to exist in the brain. From the volumes of distribution of the radioligand in the absence of displaceable binding ( $\mathrm{V}_{\mathrm{ND}}$, for "non-displaceable"), we used the three different linearizations to obtain binding potentials of radioligands used in published studies.

\section{Saturation Plot}

As a novel steady-state approach to the determination of binding potentials of tracers with an unknown reference volume of distribution, in 1995, Lassen et al. (11) proposed to compare two levels of receptor occupancy, one essentially at zero for the labeled tracer itself and the other in the mid-range of occupancy by addition of unlabeled ligand. The concentration of the unlabeled ligand in brain water would be zero in the tracer-alone study and would have a constant value in the inhibition studies. To obtain the volume of non-specific binding, Lassen 
et al. (11) linearized Equation (1) in the form of the plot we here call the Saturation Plot. The plot yields the estimate of $\mathrm{VND}_{\mathrm{ND}}$ by plotting the baseline volume of distribution $\left(\mathrm{V}_{\mathrm{T}(\mathrm{b})}\right)$, as a function of the difference between the baseline and inhibition volumes of distribution $\left(\Delta V_{T}=\right.$ $\left.\mathrm{V}_{\mathrm{T}(\mathrm{b})}-\mathrm{V}_{\mathrm{T}(\mathrm{i})}\right)$ as shown in Figure $1 \mathrm{~A}$,

$V_{T(b)}=\frac{1}{S} \Delta V_{T}+V_{N D}$

where the estimate of $\mathrm{V}_{\mathrm{ND}}$ is the ordinate intercept of the linear regression, and the estimate of the ratio $1 / \mathrm{s}$ is the slope of the regression.

\section{Inhibition Plot}

Certain receptor ligands tend altogether to lack a reference brain region of no specific binding, from which it is therefore not possible to assess non-specific binding for the purpose of calculating the binding potential in regions of specific binding. Realizing that the uncertain choice of a reference volume of distribution of the ligand can lead to an erroneous estimation of the occupancy, in 2000, Gjedde and Wong (12) proposed to linearize Equation (1) to obtain the form of the Inhibition Plot. The plot yields the estimate of $V_{N D}$ by relating the inhibited volume $\mathrm{V}_{\mathrm{T}(\mathrm{i})}$ to the baseline volume $\mathrm{V}_{\mathrm{T}(\mathrm{b})}$ by linear regression, as shown in Figure $1 \mathrm{~B}$,

$V_{T(i)}=(1-s) V_{T(b)}+s V_{N D}$

where the estimate of $V_{N D}$ is the intercept of the linear regression line with $d$ the line of identity.

\section{Occupancy Plot}

In 2010, Cunningham et al. (13) inverted the axes of the Saturation Plot and showed that the graphical analysis of the inverted relationship at each of the different doses of unlabeled 
ligand provided a means to determine drug occupancies. The inversion of the axes of the Saturation Plot was presented as the Occupancy Plot, a term we adopt here to avoid the lack of specificity of the term "Lassen Plot". The linearization known as the Occupancy Plot treats the differences between the volumes of distribution at the baseline and challenge conditions, $\Delta \mathrm{V}_{T}$, as a function of the baseline volume of distribution, as shown in Figure 1C,

$\Delta \mathrm{V}_{T}=s V_{T(b)}-s V_{N D}$

where $V_{\mathrm{ND}}$ is the abscissa intercept. It is evident from the derivations that the Saturation and Occupancy plots have mutually inverted axes.

\section{Source of Published Data}

In order to use any one of the three linearizations, at least two consecutive PET recordings with two different levels of receptor occupancy are required. For the Inhibition plot, unlike the Saturation and Occupancy plots, the dependent $\left(\mathrm{V}_{\mathrm{T}(\mathrm{i})}\right)$ and independent $\left(\mathrm{V}_{\mathrm{T}(\mathrm{b})}\right)$ variables are not commingled. The estimates of the fractional receptor availability (1-s) and $\mathrm{V}_{\mathrm{ND}}$ are then obtained directly from the volumes of distribution. As the three linearizations are derived from the same original relative receptor availability formulation (Equation (1)), they must all meet the requirements that there are different brain regions with different receptor densities $\left(B_{\max }\right)$ that remain unchanged in the challenge condition, and that the values of receptor affinity $\left(K_{D}\right)$ and non-displaceable binding volumes $\left(\mathrm{V}_{\mathrm{ND}}\right)$ are the same for all the relevant regions and remain the same for all the challenges.

To assess the advantages and disadvantages of each of the three linearizations, the following names were searched in PubMed and Scopus databases, including "Lassen plot", "Saturation 
plot", "Gjedde plot", "Inhibition plot", "Cunningham plot", and "Occupancy plot". In the initial search, 60 published reports were found. The original data sets were not available for 36 of the identified studies.

\section{Linear Regressions of Published Data}

We analyzed the 24 remaining published reports that consisted of 104 sets of data. In seven cases, the authors submitted data $(8,17-22)$, and for the remaining 17 reports, we extracted the data from published graphs with GetData Graph Digitizer digitization software $(11,13,23$ 37). The characterization of the data in terms of species, sex, age, drug, dose, and other identifiers is presented in Table 1. We used two linear regression methods, the Least Squares Method (LSM) and the Deming II method (DM), to obtain parameter estimates, as implemented in MATLAB (Mathworks). Using slope and intercept estimates, we determined s (occupancy) and $\mathrm{V}_{\mathrm{ND}}$ (volume of distribution of non-displaceable ligand), and evaluated the accuracy.

The LSM is a standard approach in regression analysis with its most important application in data fitting. The best fit of the LSM minimizes the sum of squared residuals that are the

differences between an observed value and the value fitted by the model. In LSM, two variables $(\mathrm{x}, \mathrm{y})$ are obtained by regression of $\mathrm{y}$ on $\mathrm{x}$ where $\mathrm{x}$ is assumed to represent independent variable values obtained without error (38). Deming II regression (DM) is an errors-in-variables model that yields the line of best fit for a two-dimensional dataset. It differs from LSM by the assumption of errors in both independent and dependent variables that allow for any number of predictors and a more complicated error structure. In DM, observations are subject to additive random variations of both $\mathrm{x}$ and $\mathrm{y}(39,40)$. 
In order to test the goodness of fit of the linear regressions, we calculated the coefficient of determination $\left(\mathrm{R}^{2}\right)$, coefficient of variation (RMSE), and the infinity Norm $\left(\|X\|_{\infty}\right)$. The $\mathrm{R}^{2}$ estimate is a commonly used indicator of the goodness of fit that is applicable only to the Least Squares method, as in other applications it may result in negative values or values greater than unity. In contrast, the RMSE is applicable to all linear regressions. For $n$ sets of $\left(\mathrm{x}_{i} ; \mathrm{y}_{\mathrm{i}}\right)$ data, the RMSE, $\mathrm{R}^{2}$, and $\|X\|_{\infty}$ measures can be expressed according to Rawlings et al. (38):

$R^{2}=1-\frac{S S_{\text {res }}}{S S_{\text {tot }}}$

$R M S E=\sqrt{S S_{\text {res } / n}}$

where $n$ is the number of observations, and

$\|X\|_{\infty}=\operatorname{Max}\left(f_{i}-y_{i}\right)$

where $f_{i}$ is the predicted value of $y$ at $x_{i}, S S_{\text {tot }}$ is the total sum of squares or the variance of the data,

$S S_{\text {tot }}=\sum_{i=1}^{n}\left(y_{i}-\bar{y}\right)^{2}$

and $S S_{\text {res }}$ is sum of squares of residuals,

$S S_{\text {res }}=\sum_{i=1}^{n}\left(f_{i}-y_{i}\right)^{2}$

and $\bar{y}$ is the mean of $y_{i}$.

$\bar{y}=\frac{1}{n} \sum_{i=1}^{n} y_{i}$

The closer the value of $R^{2}$ is to unity, the better the fit is to the linearization. The closer RMSE and $\|X\|_{\infty}$ values are to zero, the better the fit of the linearization is held to be $(38,41)$. 


\section{Calculation and Evaluation of Binding Potentials}

We compared binding potential estimates (BPND) for the baseline (BPND Base) and inhibition (BP ${ }_{N D}$ Challenge) conditions according to Equation (3). In total, we compared 104 times 12, or 1248 , sets of $B P_{N D}$ estimates according, first, to the equation for the percentage differences of the LSM and DM results for each of the three linearizations, exemplified here for the Inhibition Plot as,

$\Delta D_{(\text {Inhib })}=100 \frac{B P_{(L S)}-B P_{(D m)}}{\left(B P_{(L S)}+B P_{(D m)}\right) / 2}$

and, second, according to the equation for the percentage differences of the three linearizations of each of the two regression methods, exemplified here for the comparison of Least Squares and Deming II results for the Inhibition and Occupancy plots,

$\Delta D_{(L S)}=100 \frac{B P_{(\text {Inhib })}-B P_{(\text {occup })}}{\left(B P_{(\text {Inhib })}+B P_{(\text {occup })}\right) / 2}$

and,

$\Delta D_{(\text {Dm })}=100 \frac{B P_{(\text {Inhib })}-B P_{(\text {occup })}}{\left(B P_{(\text {Inhib })}+B P_{(\text {occup })}\right) / 2}$

\section{Goodness of Fit}

We considered sets of data $\left(\mathrm{V}_{\mathrm{T}(\mathrm{b})}, \mathrm{V}_{\mathrm{T}(\mathrm{i})}\right)$, directly measured in relevant studies. Due to sources of error that include surgery, environment, device errors, we predicted differences to exist between the theoretical but unknown value of a parameter and the measured value (42). We expressed the theoretical value of a parameter as $\left(\mathrm{V}_{T(\mathrm{~b})}, \mathrm{V}_{\mathrm{T}(\mathrm{i})}\right)$, 
$V_{T(i)}^{*}=V_{T(i)}-e_{1}$

and

$V_{T(b)}^{*}=V_{T(b)}-e_{2}$

where $e_{1}$ are $e_{2}$ the differences between real and measured values of $\mathrm{V}_{\mathrm{T}(\mathrm{b})}$ and $\mathrm{V}_{\mathrm{T}(\mathrm{i}) \text {, }}$ respectively. We expressed the real value of the differences between baseline and inhibition volumes of distribution as $\Delta V_{T}^{*}$,

$\Delta V_{T}^{*}=V_{T(i)}^{*}-V_{T(b)}^{*}$

which after substitution yielded,

$\Delta V_{T}^{*}=\left(V_{T(i)}-e_{1}\right)-\left(V_{T(b)}-e_{2}\right)$

or

$\Delta V_{T}^{*}=\left(V_{T(i)}-V_{T(b)}\right)-\left(e_{1}-e_{2}\right)$

that yielded,

$\Delta V_{T}^{*}=\left(V_{T(i)}-V_{T(b)}\right)-\left(e_{3}\right)$

where $\mathrm{e}_{3}$ refers to the differences between the real and measured values of $\Delta \mathrm{V}_{\mathrm{T}}$.

\section{Source of Convergence}

In this research we defined the closeness of the fitted model to the data as convergence. For the set of $\left(x_{i} ; y_{i}\right)$, regardless of method, the linearization has the form,

$y=a x+b$

with the real values in the equation expressed as,

$y=a^{*} x+b^{*}$ 
where $(a, b)$ are the estimated values of slope and ordinate intercept and $\left(a^{*}, b^{*}\right)$ are the real values of slope and ordinate intercept. As discussed, the measurement error of $\left(\mathrm{x}_{\mathrm{i}} ; \mathrm{y}_{\mathrm{i}}\right)$, yields a difference between real and estimated values of slope and ordinate intercept as,

$a^{*}=a-e_{1}^{*}$

and

$b^{*}=b-e_{2}^{*}$

where $e_{1}^{*}$ is the error between real and estimated values of slope and ordinate intercept. By substituting Equations (20) and (21) in the three original equations ((4), (5), and (6)), we calculated the differences between real and estimated values of $s$ and $V_{N D}$. Here, $s$ and $V_{N D}$ are the estimated and $\mathrm{s}^{*}$ and $\mathrm{VND}_{\mathrm{N}}{ }^{*}$ the real (unknown) values. The differences of real and estimated values of $s$ and $V_{N D}$ are listed in Table 2.

\section{RESULTS}

\section{Digitization Accuracy}

We compared the linearization of data obtained from the authors directly or by digitization of published graphs. With the submitted data available for comparison, we showed the mean error of digitization to be less than $0.85 \%$, confirming the accuracy of the digitization. Here, we present the results from the analysis of the digitized values of $\mathrm{V}_{T(\mathrm{~b})}$ and $\Delta \mathrm{V}_{T}$ from the report of Horti et al. (17), used to obtain the $\mathrm{V}_{\mathrm{T}(\mathrm{i})}$ values for the $0.5 \mathrm{mg}$ receptor inhibitor challenge. With the Inhibition, Saturation, and Occupancy linearizations for the LSM and Deming II regressions, we obtained the parameter values from the linear regressions of the data presented in Figure 1, with the resulting regressions and estimates of $s$ and $V_{N D}$ presented in Figure 2. For the Saturation Plot, we used $\Delta \mathrm{V}_{\mathrm{T}}$ as the independent variable $(\mathrm{X})$, and $\mathrm{V}_{\mathrm{T}(\mathrm{b})}$ as 
the dependent variable $(\mathrm{Y})$, while for the Occupancy plot, we used $\Delta \mathrm{V}_{\mathrm{T}}$ as the dependent variable $(\mathrm{Y})$, and $\mathrm{V}_{\mathrm{T}(\mathrm{b})}$ as the independent variable $(\mathrm{X})$.

\section{Plot Analysis}

Using the linearization goodness of fit parameters $\mathrm{R}^{2}, \mathrm{RMSE}$, and $\|X\|_{\infty}$, the comparisons yielded the results listed in Table 3 and Figure 2. The mean value of $R^{2}$ (for the 104 samples) of the Inhibition Plot was slightly closer to unity, identifying the Inhibition Plot as the plot with slightly greater fit to the experimental data. In addition, the mean values of RMSE and $\|X\|_{\infty}$ of the Inhibition Plot were closest to zero, again as the most accurate of the three plots. In 87 of the 104 cases, the Inhibition Plot yielded the lowest RMSE and $\|X\|_{\infty}$ values, implying that the Inhibition Plot had superior accuracy in the 87 cases.

The effects of regression method (Least Squares or Deming II) on the estimated values of s, $\mathrm{V}_{N D}$, and $B P_{N D}$ are shown in Figure 3. The estimates of $s, V_{N D}$, and $B P_{N D}$ of the two regression methods (Least Squares and Deming II) generally converged. The average deviation was less than $0.1 \%$ for $s$ and $V_{N D}$, and less than $3 \%$ for $\mathrm{BP}_{\mathrm{ND}}$. We also compared the effects of choice of method on the estimated values of $\mathrm{s}, \mathrm{V}_{\mathrm{ND}}$, and BP $\mathrm{ND}_{\mathrm{ND}}$. The deviations of $\mathrm{s}, \mathrm{V}_{\mathrm{ND}}$, and $\mathrm{BP}_{\mathrm{ND}}$ for the three plots (Inhibition, Saturation and Occupancy) are shown in Figure 3. From the figure, we conclude that the results of the Inhibition and Occupancy plots normally converged for both the Least squares and Deming regressions. The average difference of the Inhibition and Occupancy plot results was less than $2 \%$. In contrast, we generally found considerable differences between the results of the Saturation Plot and the Inhibition and Occupancy plots. The average difference shown in Figure 3 is close to $40 \%$. 
Bland-Altman graphs for the binding potentials determined with $0.5 \mathrm{mg}$ receptor inhibitor blockade by Horti et al. (17) are shown in supplemental Figure 1.

\section{Goodness of Fit}

We considered sets of data $\left(\mathrm{V}_{T(b)}, \mathrm{V}_{T(i)}\right)$, directly measured in relevant studies. Due to sources of error that include surgery, environment, device errors, we predicted differences to exist between the real but unknown value of a parameter and the measured value (42). We expressed the real value of a parameter as $\left(\mathrm{V}_{\mathrm{T}(\mathrm{b})}, \mathrm{V}_{\mathrm{T}(\mathrm{i})}\right)$,

$V_{T(i)}^{*}=V_{T(i)}-e_{1}$

and

$V_{T(b)}^{*}=V_{T(b)}-e_{2}$

where $e_{1}$ are $e_{2}$ the differences between real and measured values of $\mathrm{V}_{T(\mathrm{~b})}$ and $\mathrm{V}_{\mathrm{T}(\mathrm{i}) \text {, }}$ respectively. We expressed the real value of the differences between baseline and inhibition volumes of distribution as $\Delta V_{T}^{*}$,

$\Delta V_{T}^{*}=V_{T(i)}^{*}-V_{T(b)}^{*}$

which after substitution yielded,

$\Delta V_{T}^{*}=\left(V_{T(i)}-e_{1}\right)-\left(V_{T(b)}-e_{2}\right)$

or

$\Delta V_{T}^{*}=\left(V_{T(i)}-V_{T(b)}\right)-\left(e_{1}-e_{2}\right)$

that yielded,

$\Delta V_{T}^{*}=\left(V_{T(i)}-V_{T(i)}\right)-\left(e_{3}\right)$

where e $_{3}$ refers to the differences between the real and measured values of $\Delta \mathrm{V}_{\mathrm{T}}$. 


\section{Sources of Convergence}

For the set of $\left(\mathrm{x}_{i} ; \mathrm{y}_{\mathrm{i}}\right)$, regardless of method, the linearization has the form,

$y=a x+b$

with the real values in the equation expressed as,

$y=a^{*} x+b^{*}$

where $(a, b)$ are the estimated values of slope and ordinate intercept and $\left(a^{*}, b^{*}\right)$ are the real values of slope and ordinate intercept. As discussed, the measurement error of $\left(x_{i} ; y_{i}\right)$, yields a difference between real and estimated values of slope and ordinate intercept as,

$a^{*}=a-e_{1}^{*}$

and

$b^{*}=b-e_{2}^{*}$

where $e_{1}^{*}$ is the error between real and estimated values of slope and ordinate intercept. By substituting Equations (20) and (21) in the three original equations ((4), (5), and (6)), we calculated the differences between real and estimated values of $s$ and $V_{N D}$. Here, $s$ and $V_{N D}$ are the estimated and $\mathrm{s}^{*}$ and $\mathrm{VND}^{*}$ are the real (unknown) values. The differences of real and estimated values of $\mathrm{s}$ and $\mathrm{V}_{\mathrm{ND}}$ are listed in Table 3.

\section{Analysis of Noise Simulation}

To investigate the effect of noise on the convergence of the results of different plots, two sets of theoretical data (data without noise) were created on the basis of the Horti et al. (17) data at two levels of inhibition ( 0.5 and $5 \mathrm{mg}$ inhibitor administration). We considered five sets of data, and calculated the values of occupancy $(s)$, nondisplaceable volume of distribution ( $V_{\mathrm{ND}}$ ) using the three plots and two different linearizations (data without noise, with noise $K=0.1$, 
$\mathrm{K}=0.2, \mathrm{~K}=0.5$, and experimental data) where $\mathrm{K}$ is the chosen standard deviation. The results of the linearizations are listed in Supplemental Table 1 and Supplemental Figure 2. As shown in Supplemental Figure 3, for the data without noise, all three plots and two linearizations yield identical results. For the convergence of the three plots, it is evident that the RMSE of the data without noise for all three plots is approximately zero $\left(10^{-9}\right)$. However, as is shown in Supplemental Figure 4, in the presence of noise, the Inhibition and Occupancy plots yielded lower RMSE, consistent with greater convergence.

\section{DISCUSSION}

In the present examination of the plots of competition, we linearized the formulation of the fractional receptor availability (Equation (1)) into three equations underlying the different regressions that we refer to as the Saturation, Inhibition, and Occupancy plots. The purpose of all three linearizations is to obtain an estimate of the reference volume of distribution $\mathrm{V}_{\mathrm{ND}}$, required to calculate the binding potential of a radioligand. We undertook the comparisons because the extent to which the results of the three plots converge or diverge is unknown. We culled 104 cases reported on the basis of one or more of the plots, and we tested the results of the three plots linearized by Least squares and Deming II regressions.

As shown in Table 3, for both $\mathrm{s}$ and $\mathrm{VND}$, the differences of estimated and real values are of the same order of magnitude for the Inhibition and Occupancy plots but are much greater for the Saturation Plot. For this reason, the average deviation of calculated values of $s$ and $V_{N D}$ of the Inhibition and Occupancy plots was less than $0.1 \%$, and the results generally converged. In contrast, there was more than 35\% difference between the results of the Saturation and the results of the Inhibition and Occupancy plots. In Equations (16-18), $e_{1}, e_{2}$, and $e_{3}$ are the error values resulting from the divergence of individual plots. The parameter $e_{3}$ may be smaller 
than $e_{1}$ and $e_{2}$, but frequently is not. As $e_{1}$ and $e_{2}$ do not adopt exclusively positive or negative values, errors can be superimposed. For this reason, the use of $\Delta \mathrm{V}_{\mathrm{T}}$ differences may result in higher levels of error and reductions of goodness of fit. Among the three methods, the Inhibition Plot avoided the use of the commingled variable $\Delta \mathrm{V}_{\mathrm{T}}$. As expressed by the three indicators $\mathrm{R}^{2}, \mathrm{RMSE}$, and $\|X\|_{\infty}$, the Inhibition Plot was shown to yield slightly greater fit for both Least Squares and Deming II methods. The noise analysis showed that, the Inhibition and Occupancy plots yielded higher convergence in the presence of noise.

\section{CONCLUSION}

Based on the all 3 of the goodness of fit parameters $\left(\mathrm{R}^{2}, \mathrm{RMSE}\right.$, and $\left.\|X\|_{\infty}\right)$ and with both regression methods (Least Squares and Deming II), the Inhibition plots emerged as the plot with slightly higher degree of convergence. We judge this to be because of the absent commingling of the original dependent and independent variables of the Saturation (original "Lassen") plot. Concerning the effect of regression method (Least squares and Deming II) on the estimated values of $\mathrm{s}, \mathrm{V}_{\mathrm{ND}}$, and $\mathrm{BP} \mathrm{ND}$, we observed that the average differences of results of the Inhibition and Occupancy plot linearizations were less than $0.1 \%$ and as such negligible. In contrast, we noted more than $35 \%$ difference between the results of the Saturation plot comparisons that we explain by the violation of the negligible variability rule for independent variables. The noise analysis showed that the three plots resulted in the same

parameter estimates in the absence of the noise, However, in the presence of noise, the Inhibition and Occupancy plots yielded higher and close degrees of convergence. 


\section{Disclosure}

\section{Author contributions statement}

J.Kh and A.Gj conducted the data analysis and regression. M.AK, M.SV, and D.FW collected and extracted the data from the literature. J.Kh, M.AK, and A.Gj were responsible for the manuscript writing. A.Gj conceived of the study. All authors read and approved the final manuscript.

\section{Competing interests}

Authors declare no conflicts of interest.

\section{Funding}

This study was supported by Parkinsonforeningen, Lundbeckfonden (R77-A6970), and the Danish Agency for Science and Higher Education.

\section{Ethics approval and consent to participate}

This article does not contain any studies with human participants or animals of which any one of the authors is responsible.

\section{Data availability}

The datasets generated during and/or analyzed during the current study are available from the corresponding author on reasonable request. 


\section{KEY POINTS}

Question: Which of the three linearizations (Inhibition, Saturation, and Occupancy) had superior convergence to the experimental results?

Pertinent Findings: Superior convergences among the values of s, VND, and BPND for the Inhibition and Occupancy plots were observed. Based on the goodness of fit parameters $\left(R^{2}\right.$, RMSE, and $\|X\|_{\infty}$ ) and with both regression methods (Least squares and Deming II), the Inhibition Plot emerged as the plot with the slightly higher degree of convergence.

Implications for Patient Care: The correct use of the Occupancy and Inhibition plots allows brain imaging specialists to advise on the optimal dose of target engagement of neuroreceptor inhibitor drugs chosen to block the pathological excess of neurotransmission. 


\section{REFERENCES}

1. Ter-Pogossian MM. Positron emission tomography. Biomedical Images and Computers: Springer; 1982. p. 216-24.

2. Gjedde A, Wong DF, Rosa-Neto P, Cumming P. Mapping neuroreceptors at work: on the definition and interpretation of binding potentials after 20 years of progress. Int Rev Neurobiol. 2005;63:1-20.

3. Wahl RL, editor Current status of PET in breast cancer imaging, staging, and therapy. Seminars in Roentgenology. 2001;36:250-260

4. Wong DF, Gjedde A, Wagner Jr HN. Quantification of neuroreceptors in the living human brain. I. Irreversible binding of ligands. J. Cereb. Blood Flow Metab. 1986;6:137-46.

5. Phan J-A, Landau AM, Jakobsen S, Wong DF, Gjedde A. Radioligand binding analysis of a 2 adrenoceptors with [11 C] yohimbine in brain in vivo: Extended Inhibition Plot correction for plasma protein binding. Scientific reports. 2017;7:1-17.

6. Naganawa M, Gallezot J-D, Rossano S, Carson RE. Quantitative PET imaging in drug development: estimation of target occupancy. Bull. Math. Biol . 2019;81:3508-41.

7. Gjedde A, Wong DF, Wagner Jr HN. Transient analysis of irreversible and reversible tracer binding in human brain in vivo. PET and NMR: New Perspectives in Neuroimaging and in Clinical Neurochemistry New York, NY: AR Liss. 1986;6:223-35.

8. Phan J-A, Landau AM, Wong DF, et al. Quantification of [11C] yohimbine binding to a2 adrenoceptors in rat brain in vivo. J. Cereb. Blood Flow Metab. 2015;35:501-11.

9. Landau AM, Alstrup AK, Audrain $\mathrm{H}$, et al. Elevated dopamine D1 receptor availability in striatum of Göttingen minipigs after electroconvulsive therapy. J. Cereb. Blood Flow Metab. 2018;38:881-7.

10. DeLorenzo C, Gallezot J-D, Gardus J, et al. In vivo variation in same-day estimates of metabotropic glutamate receptor subtype 5 binding using [11C] ABP688 and [18F] FPEB. J. Cereb. Blood Flow Metab. 2017;37:2716-27.

11. Lassen N, Bartenstein $P$, Lammertsma $A$, et al. Benzodiazepine receptor quantification in vivo in humans using [11C] flumazenil and PET: application of the steady-state principle. J. Cereb. Blood Flow Metab. 1995;15:152-65.

12. Gjedde A, Wong D. Receptor occupancy in absence of reference region. Neuroimage. 2000;11:S48.

13. Cunningham VJ, Rabiner EA, Slifstein M, Laruelle M, Gunn RN. Measuring drug occupancy in the absence of a reference region: the Lassen plot re-visited. J. Cereb. Blood Flow Metab. 2010;30:46-50.

14. Mintun MA, Raichle ME, Kilbourn MR, Wooten GF, Welch MJ. A quantitative model for the in vivo assessment of drug binding sites with positron emission tomography. Annals of Neurology: Official Journal of the American Neurological Association and the Child Neurology Society. 1984;15:217-27.

15. Karalija N, Jonassson L, Johansson J, et al. High long-term test-retest reliability for extrastriatal 11C-raclopride binding in healthy older adults. J. Cereb. Blood Flow Metab. 2020;40:1859-68.

16. Innis RB, Cunningham VJ, Delforge $J$, et al. Consensus nomenclature for in vivo imaging of reversibly binding radioligands. J. Cereb. Blood Flow Metab. 2007;27:1533-9.

17. Horti AG, Gao Y, Kuwabara H, et al. 18F-ASEM, a radiolabeled antagonist for imaging the a7-nicotinic acetylcholine receptor with PET. Journal of Nuclear Medicine. 2014;55:672-7.

18. Ramakrishnan NK, Schepers M, Luurtsema G, et al. Cutamesine overcomes REM sleep deprivation-induced memory loss: relationship to sigma-1 receptor occupancy. Molecular Imaging and Biology. 2015;17:364-72.

19. Ettrup A, Mikkelsen JD, Lehel S, et al. 11C-NS14492 as a novel PET radioligand for imaging cerebral a7 nicotinic acetylcholine receptors: in vivo evaluation and drug occupancy measurements. Journal of Nuclear Medicine. 2011;52:1449-56.

20. Narendran R, Mason NS, Chen CM, et al. Evaluation of dopamine D2/3specific binding in the cerebellum for the positron emission tomography radiotracer [11C] FLB 457: Implications for measuring cortical dopamine release. Synapse. 2011;65:991-7.

21. Wong DF, Kuwabara H, Horti AG, et al. Brain PET imaging of a7-nAChR with [18F] ASEM: reproducibility, occupancy, receptor density, and changes in schizophrenia. International Journal of Neuropsychopharmacology. 2018;21:656-67.

22. Koole M, van Aalst J, Devrome M, et al. Quantifying SV2A density and drug occupancy in the human brain using [11 C] UCB-J PET imaging and subcortical white matter as reference tissue. Eur. J. Nucl. Med. Mol. Imaging. 2019;46:396-406.

23. Owen DR, Guo Q, Kalk NJ, et al. Determination of [11C] PBR28 binding potential in vivo: a first human TSPO blocking study. J. Cereb. Blood Flow Metab. 2014;34:989-94.

24. Naganawa M, Jacobsen LK, Zheng M-Q, et al. Evaluation of the agonist PET radioligand [11C] GR103545 to image kappa opioid receptor in humans: Kinetic model selection, test-retest reproducibility and receptor occupancy by the antagonist PF-04455242. Neuroimage. 2014;99:69-79. 
25. Kågedal M, Cselényi Z, Nyberg S, et al. A positron emission tomography study in healthy volunteers to estimate mGluR5 receptor occupancy of AZD2066-estimating occupancy in the absence of a reference region. Neuroimage. 2013;82:160-9.

26. Jucaite A, Takano A, Boström E, et al. AZD5213: a novel histamine $\mathrm{H} 3$ receptor antagonist permitting high daytime and low nocturnal $\mathrm{H} 3$ receptor occupancy, a PET study in human subjects. International Journal of Neuropsychopharmacology. 2013;16:1231-9.

27. Elmenhorst D, Meyer PT, Matusch A, Winz OH, Bauer A. Caffeine occupancy of human cerebral A1 adenosine receptors: in vivo quantification with 18F-CPFPX and PET. Journal of Nuclear Medicine. 2012;53:1723-9.

28. Ridler K, Plisson C, Rabiner EA, et al. Characterization of in vivo pharmacological properties and sensitivity to endogenous serotonin of [11C] P943: a positron emission tomography study in Papio anubis. Synapse. 2011;65:111927.

29. Fuchigami T, Takano A, Gulyás B, et al. Synthesis and evaluation of 2-chloro N-[(S)-\{(S)-1-[11 C] methylpiperidin-2yl\}(phenyl) methyl] 3-trifluoromethyl-benzamide ([11 C] N-methyl-SSR504734) as a PET radioligand for glycine transporter 1. EJNMMI research. 2012;2:37.

30. Logan J, Kim SW, Pareto D, et al. Kinetic analysis of [11C] vorozole binding in the human brain with positron emission tomography. Molecular imaging. 2014;13:7290.

31. Martin-Facklam M, Pizzagalli F, Zhou Y, et al. Glycine transporter type 1 occupancy by bitopertin: a positron emission tomography study in healthy volunteers. Neuropsychopharmacology. 2013;38:504-12.

32. Myers JF, Rosso L, Watson BJ, et al. Characterisation of the contribution of the GABA-benzodiazepine a1 receptor subtype to [11C] Ro15-4513 PET images. J. Cereb. Blood Flow Metab. 2012;32:731-44.

33. Phan J-A, Jakobsen S, Landau AM, Doudet D, Gjedde A. Amphetamine-induced inhibition of [C-11] yohimbine binding in rat brain. The Ninth International Symposium on Functional Neuroreceptor Mapping of the Living Brain (NRM2012); 2012;32:S98-S99.

34. Visser AK, De Vries EF, Ramakrishnan NK, et al. Analysis of 5-HT 2A receptor binding with [11 C] MDL 100907 in rats: optimization of kinetic modeling. Molecular imaging and biology. 2013;15:730-8.

35. Milak MS, Severance AJ, Prabhakaran J, et al. In vivo serotonin-sensitive binding of [11C] CUMI-101: a serotonin $1 \mathrm{~A}$ receptor agonist positron emission tomography radiotracer. J. Cereb. Blood Flow Metab. 2011;31:243-9.

36. Hillmer AT, Zheng M-Q, Li S, et al. PET imaging evaluation of [18 F] DBT-10, a novel radioligand specific to a 7 nicotinic acetylcholine receptors, in nonhuman primates. European journal of nuclear medicine and molecular imaging. 2016;43:537-47.

37. Paul S, Khanapur S, Sijbesma JW, et al. Use of 11C-MPDX and PET to study adenosine A1 receptor occupancy by nonradioactive agonists and antagonists. Journal of Nuclear Medicine. 2014;55:315-20.

38. Rawlings JO, Pantula SG, Dickey DA. Applied regression analysis: a research tool: Springer Science \& Business Media; 2001;2-6

39. Deming WE. Statistical adjustment of data. 1943;59-127

40. Linnet K. Estimation of the linear relationship between the measurements of two methods with proportional errors. Statistics in Medicine. 1990;9:1463-73.

41. Epperson JF. An introduction to numerical methods and analysis: John Wiley \& Sons; 2013;442-444

42. Sydenham PH, Thorn R. Handbook of measuring system design2005;289-300 


\begin{tabular}{|c|c|c|c|c|c|c|c|c|c|c|c|c|}
\hline Source & Cite & $\begin{array}{l}\text { Case } \\
\text { No. }\end{array}$ & $\begin{array}{l}\text { Data } \\
\text { No. }\end{array}$ & Type & Male & Female & Age & Weight (Kg) & Drug or Material & Doses & $\begin{array}{c}\text { Duration } \\
\text { (Hours) }\end{array}$ & Tracer \\
\hline Owen et al. 23 & 92 & 10 & $7-15$ & Human & - & - & - & - & XBD173 & $10-90 \mathrm{mg}$ & - & ${ }^{11} \mathrm{C}-\mathrm{PBR} 28$ \\
\hline Naganawa et al. 24 & 35 & 2 & 13 & Human & - & - & $25-52$ & - & PF-04455242 & $30 \mathrm{mg}$ & $1.5,8$ & ${ }^{11}$ C-GR103545 \\
\hline Cunningham al. 13 & 197 & 4 & 9 & Human & - & - & - & - & $5 H T 1 A$ & $1.5,10,150 \mu \mathrm{g} / \mathrm{kg}$ & 1 & ${ }^{11}$ C-WAY100635 \\
\hline Kagedal et al. 25 & 31 & 3 & 10 & Human & - & - & - & - & AZD2066 & $3.5,6.9,13.5 \mathrm{mg}$ & - & ${ }^{11} \mathrm{C}-\mathrm{ABP} 688$ \\
\hline Jucaite et al. 26 & 28 & 2 & 9 & Human & 2 & 0 & $22-44$ & - & AZD5213 & $0.1,0.3 \mathrm{mg}$ & 2 & $\begin{array}{l}{ }^{11} \mathrm{C}-\mathrm{GSK} 189254 \\
{ }^{11} \mathrm{C}-\mathrm{AZ} 12807110\end{array}$ \\
\hline Elmenhorst al. 27 & 57 & 14 & $9-23$ & Human & - & - & $24-68$ & - & Caffeine & $0-9 \mathrm{mg} / \mathrm{kg}$ & 36 & ${ }^{18} \mathrm{~F}-\mathrm{CP}$ FPX \\
\hline Ridler et al. 28 & 24 & 6 & $12-15$ & Papio anubis & 6 & 0 & - & 22.4 & $\begin{array}{c}\text { P943, SB-616234- } \\
\text { S, SB-714786 }\end{array}$ & $25,100 \mu \mathrm{g}$ & - & ${ }^{11} \mathrm{C}-\mathrm{P} 943$ \\
\hline Fuchi gami al. 29 & 3 & 2 & 6 & $\begin{array}{l}\text { Rhesus } \\
\text { monkey }\end{array}$ & - & - & - & $4.90,5.55$ & SSR504734 & 1.5 and $4.5 \mathrm{mg} / \mathrm{kg}$ & - & $\begin{array}{l}{ }^{11} \mathrm{C}-\mathrm{N}-\text { methyl- } \\
\text { SSR504734 }\end{array}$ \\
\hline Logan et al. 30 & 4 & 1 & 7 & Human & - & - & $23-67$ & - & letrozole & $2.5 \mathrm{mg}$ & 2.5 & ${ }^{11} \mathrm{C}$-Vorozol e \\
\hline Martin et al. 31 & 38 & 5 & $26-39$ & Human & 5 & - & $20-51$ & - & Bitopertin & $5,15,30,60,175 \mathrm{mg}$ & - & ${ }^{11} \mathrm{C}-\mathrm{RO} 05013853$ \\
\hline Lassen et al. 11 & 18 & 1 & 31 & Human & 1 & 0 & $22-65$ & - & Benzodiazepines & $0.6 \mathrm{mg}$ & - & ${ }^{11} \mathrm{C}$-flumazenil \\
\hline Myers et al. 32 & 19 & 12 & 24 & Human & - & - & $\begin{array}{l}\text { AVG: } \\
43,44\end{array}$ & - & Zolpidem, Placebo & $1.37 \mu \mathrm{g}-3.71 \mu \mathrm{g}$ & 1.5 & $\begin{array}{l}{ }^{11} \mathrm{C} \text {-flumazenil, } \\
{ }^{11} \mathrm{C} \text {-Ro15-4513 }\end{array}$ \\
\hline Phan et al. 33 & 1 & 1 & 9 & $\begin{array}{c}\text { Sprague } \\
\text { Dawley rats }\end{array}$ & 0 & 1 & - & $0.225-0.250$ & Cyclosporine & $1 \mathrm{mg} / \mathrm{kg}$ & 1.5 & ${ }^{11} \mathrm{C}$-yohimbine \\
\hline Ettrup et al. 19 & 41 & 5 & 10 & $\begin{array}{c}\text { Danish } \\
\text { Landrace Pigs }\end{array}$ & 0 & 5 & - & 19 & $\begin{array}{l}\text { SSR180711 } \\
\text { NS14492 }\end{array}$ & $1,10 \mathrm{mg} / \mathrm{kg}$ & $0.5,4$ & ${ }^{11} \mathrm{C}-\mathrm{NS} 14492$ \\
\hline $\begin{array}{l}\text { Ramakrishnan et } \\
\text { al. } 18\end{array}$ & 4 & 2 & 12 & $\begin{array}{c}\text { Wistar } \\
\text { Hannover Rat }\end{array}$ & 2 & 0 & - & - & Cutamesine & $0.3,1 \mathrm{mg} / \mathrm{kg}$ & - & ${ }^{11} \mathrm{C}-\mathrm{SA} 4503$ \\
\hline Visser et al. 34 & 5 & 1 & 11 & Wistar rats & 1 & 0 & - & 0.317 & MDL 100907 & $1 \mathrm{mg} / \mathrm{ml}$ & - & ${ }^{11} \mathrm{C}-\mathrm{MDL} 100907$ \\
\hline Milak et al. 35 & 53 & 6 & 8 & Papio anubis & 6 & 0 & - & - & $\begin{array}{c}\text { Citalopram, } \\
\text { Fenfluramine }\end{array}$ & $2,2.5,4 \mathrm{mg} / \mathrm{kg}$ & - & ${ }^{11} \mathrm{C}-\mathrm{CUMM}-101$ \\
\hline Hillmer et al. 36 & 12 & 3 & 9 & $\begin{array}{l}\text { Macaca } \\
\text { mulatta }\end{array}$ & 2 & 1 & $6-15$ & $7-14$ & ASEM & $0.69,1.24 \mathrm{mg} / \mathrm{kg}$ & - & ${ }^{18} \mathrm{~F}-\mathrm{DBT}-10$ \\
\hline Paul et al. 37 & 11 & 2 & 14 & Wistar rats & 2 & 0 & - & 0.304 & CPA, Caffeine & $0.25,40 \mathrm{mg} / \mathrm{kg}$ & $15 \mathrm{~min}$ & ${ }^{11} \mathrm{C}-\mathrm{MPDX}$ \\
\hline Phan et al. 8 & 11 & 10 & 6 & $\begin{array}{c}\text { Sprague } \\
\text { Dawley,Rats }\end{array}$ & - & - & - & $0.250-0.300$ & Amphetamine & - & $6-28 \min$ & ${ }^{11} \mathrm{C}$-yohimbine \\
\hline Horti et al.17 & 41 & 2 & 16 & Baboon & 2 & 0 & - & $20.1-26.0$ & ASEM & $0.5,5 \mathrm{mg} / \mathrm{kg}$ & $5-90 \min$ & ${ }^{18} \mathrm{~F}-\mathrm{ASEM}$ \\
\hline Narendran et al. 20 & 28 & 6 & 11 & Human & 5 & 1 & AVG: 24 & - & Aripiprazole & $15 \mathrm{mg}$ & 3 & ${ }^{11}$ CFLB 457 \\
\hline Koole et al.22 & 12 & 3 & 15 & Human & - & - & $20-54$ & & padsevonil & $6.25 \mathrm{mg}$ & 2 & ${ }^{11}$ C-UCB-J \\
\hline Wong et al. 21 & 12 & 1 & 20 & Human & 1 & 0 & $18-52$ & - & DMXB-A & $150 \mathrm{mg}$ & $40 \mathrm{~min}$ & ${ }^{18} \mathrm{~F}$-ASEM \\
\hline
\end{tabular}

Table 1. Categorization of data from papers included in the analysis 


\begin{tabular}{lcc}
\hline Method & $s$ & $V_{N D}$ \\
\hline Inhibition & $s^{*}+e_{1}$ & $\frac{s^{*} V_{N D}^{*}-e_{1}}{s^{*}+e_{1}}$ \\
\hline Occupancy & $s^{*}-e_{1}$ & $\frac{s^{*} V_{N D}^{*}-e_{1}}{s^{*}-e_{1}}$ \\
\hline Saturation & $\frac{s^{*}}{1-s^{*}-e_{1}}$ & $V_{N D}^{*}-e_{2}$
\end{tabular}

Table 2. Differences between real and estimated values of $s$ and $V_{N D}$ of the three methods

\begin{tabular}{llccc}
\hline Plot & Method & $\mathrm{R}^{2}$ & $\mathrm{RMSE}$ & $\|X\|_{\infty}$ \\
\hline \multirow{2}{*}{ Inhibition } & LSM & $0.75 \pm 0.25$ & $0.36 \pm 0.46$ & $0.69 \pm 0.84$ \\
\cline { 2 - 5 } & Deming & $0.75 \pm 0.25$ & $0.26 \pm 0.33$ & $0.69 \pm 0.84$ \\
\hline \multirow{2}{*}{ Saturation } & LSM & $0.73 \pm 0.29$ & $0.77 \pm 1.29$ & $1.40 \pm 2.01$ \\
\cline { 2 - 5 } & Deming & $0.73 \pm 0.29$ & $0.55 \pm 0.91$ & $1.40 \pm 2.01$ \\
\hline \multirow{2}{*}{ Occupancy } & LSM & $0.73 \pm 0.29$ & $0.36 \pm 0.46$ & $0.69 \pm 0.84$ \\
\cline { 2 - 5 } & Deming II & $0.73 \pm 0.29$ & $0.26 \pm 0.33$ & $0.69 \pm 0.84$ \\
\hline
\end{tabular}

Table 3. Average precision of regressions of the three plots 


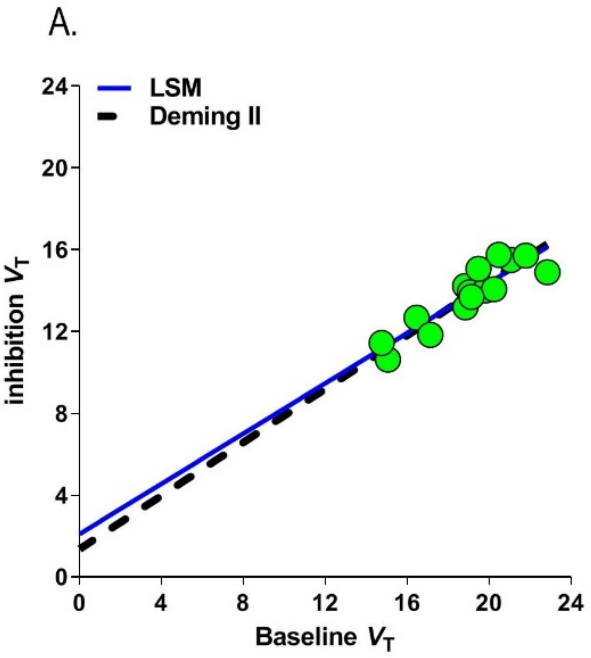

B.

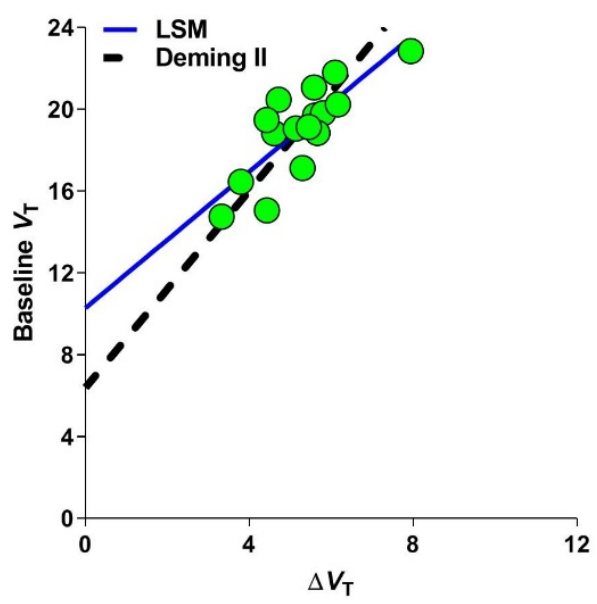

C.

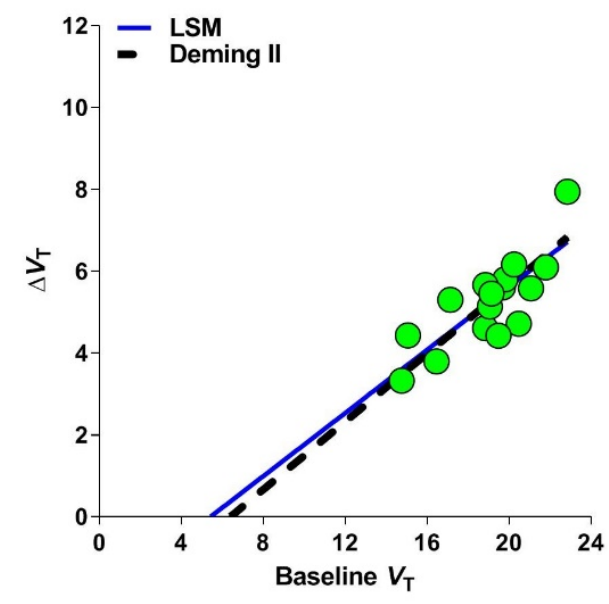

Figure 1. Linearizations of data from Horti et al. (17) (dose $0.5 \mathrm{mg}$ ) 


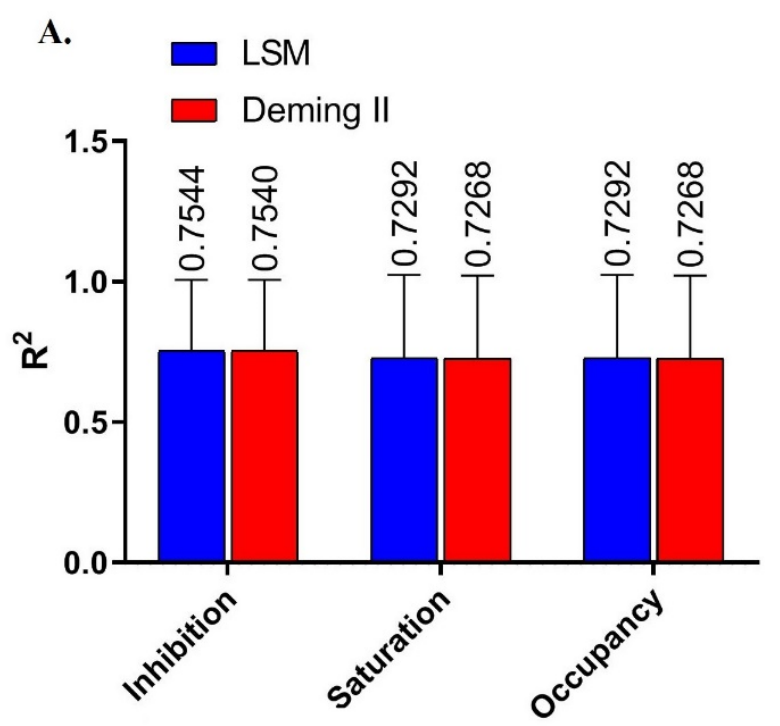

B. $\square$ Deming II

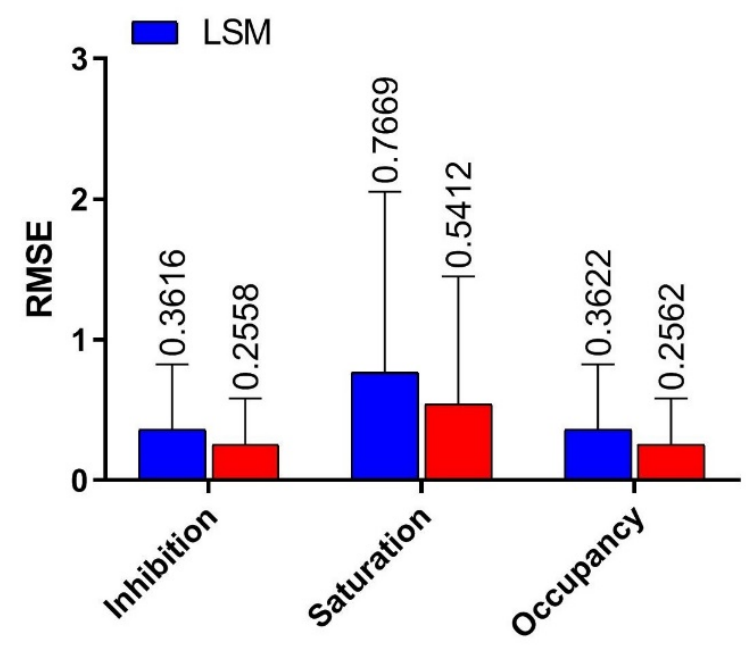

C.

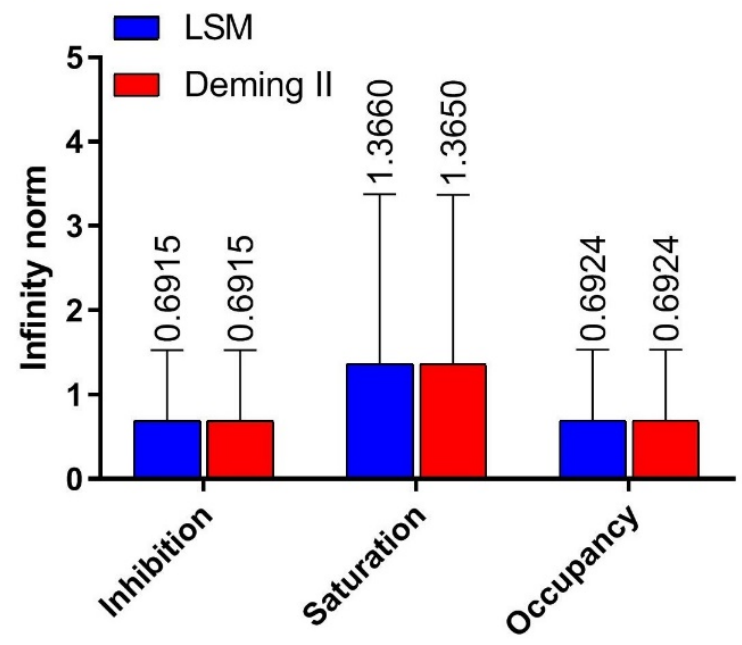

Figure 2. Average and standard deviation of goodness of fit of the three plots 
A.

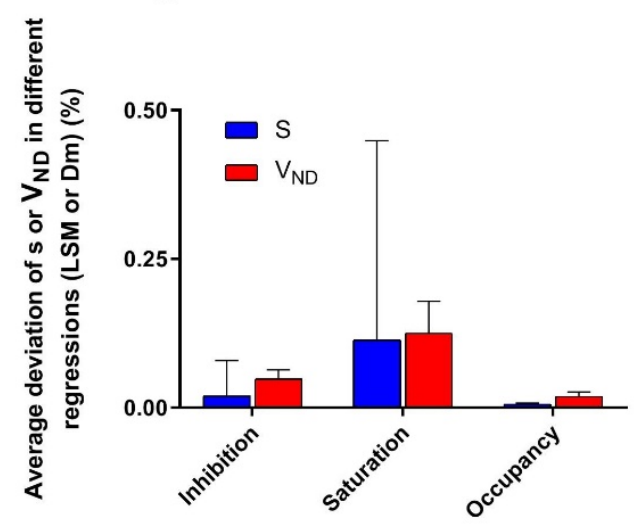

c.

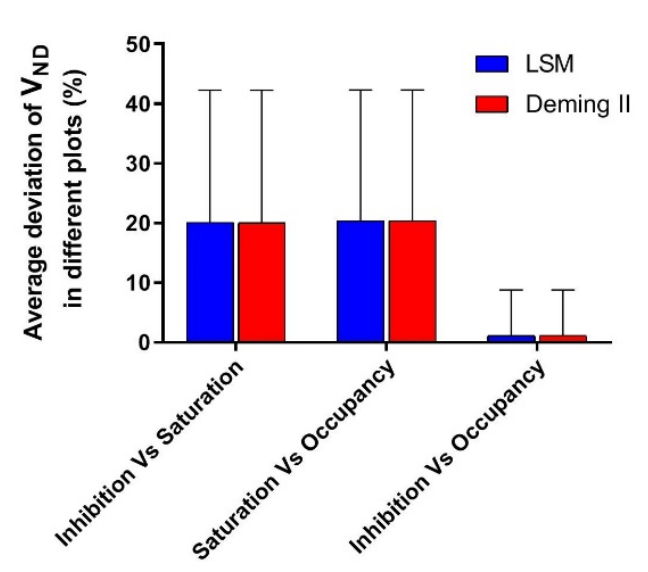

E.

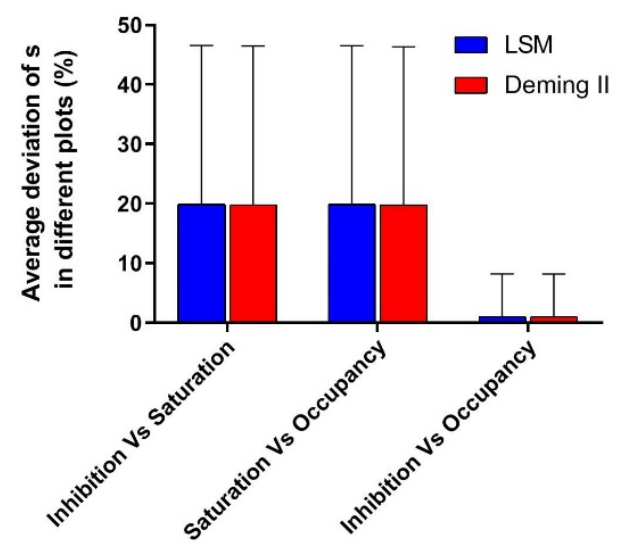

B.

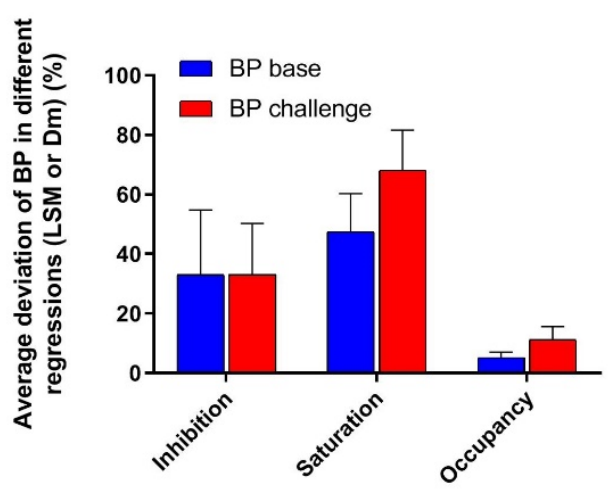

D.

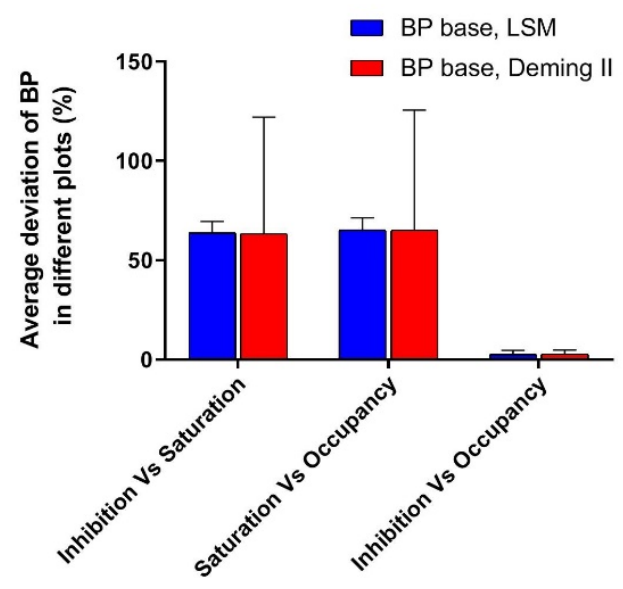

F.

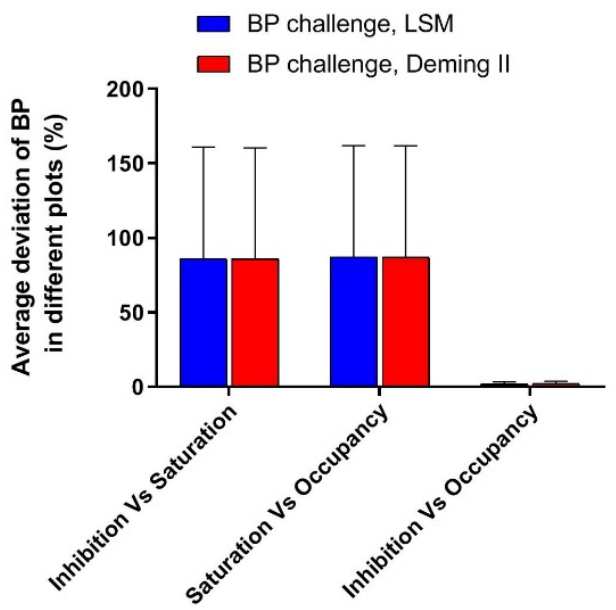

Figure 3. Differences of $s, V_{N D}$ and $B P_{N D}$ in pairwise regression comparisons (LSM \& Dm) and pairwise plot comparisons (I, S and O) (Mean and Standard Deviation). Deviation of A. $S$ and $V_{N D} L S M$ vs. Dm. B. BPND LSM vs. Dm. C. VND LSM and Dm in different plots. D. BP $P_{N D}$ Base LSM and Dm in different plots. E. s LSM and Dm in different plots. F. BPND Challenge LSM and Dm in different plots. 


\section{Supplemental Tables and Figures}

Supplemental Table 1. Effect of noise in three plots and two linearizations of data from Horti et al. (17)

\begin{tabular}{|c|c|c|c|c|c|c|c|c|c|c|c|}
\hline & & & \multicolumn{3}{|c|}{ Inhibition } & \multicolumn{3}{|c|}{ Occupancy } & \multicolumn{3}{|c|}{ Saturation } \\
\hline & & & $\boldsymbol{s}$ & $V_{N D}$ & $R M S E$ & $s$ & $V_{N D}$ & $R M S E$ & $s$ & $V_{N D}$ & $R M S E$ \\
\hline \multirow{10}{*}{ LSM } & \multirow{5}{*}{$\begin{array}{l}0.5 \\
\mathrm{mg}\end{array}$} & Theoretical (no noise) & 0.3857 & 5.4284 & 0.000000 & 0.3857 & 5.4284 & 0.000000 & 0.3857 & 5.4284 & 0.000000 \\
\hline & & Noise $(K=0.1)$ & 0.3728 & 4.7845 & 0.236853 & 0.3728 & 4.7845 & 0.236853 & 0.3799 & 5.0540 & 0.630585 \\
\hline & & Noise $(K=0.2)$ & 0.3891 & 5.5287 & 0.431700 & 0.3891 & 5.5287 & 0.431700 & 0.4172 & 6.4369 & 1.061096 \\
\hline & & Noise $(K=0.5)$ & 0.4568 & 7.5947 & 0.952075 & 0.4568 & 7.5947 & 0.952075 & 0.5167 & 8.9220 & 2.273353 \\
\hline & & Experimental & 0.3857 & 5.4284 & 1.227867 & 0.3857 & 5.4284 & 1.227867 & 0.5999 & 10.2899 & 2.616056 \\
\hline & \multirow{5}{*}{$\begin{array}{c}5 \\
\mathrm{mg}\end{array}$} & Theoretical (no noise) & 0.8205 & 0.8007 & 0.000000 & 0.8205 & 0.8007 & 0.000000 & 0.8205 & 0.8007 & 0.000000 \\
\hline & & Noise $(K=0.1)$ & 0.8201 & 0.8033 & 0.199058 & 0.8201 & 0.8033 & 0.199058 & 0.8228 & 0.8639 & 0.235100 \\
\hline & & Noise $(K=0.2)$ & 0.8219 & 0.8832 & 0.405815 & 0.8219 & 0.8832 & 0.405815 & 0.8357 & 1.1824 & 0.482307 \\
\hline & & Noise $(K=0.5)$ & 0.9526 & 3.2904 & 0.481152 & 0.9526 & 3.2904 & 0.481152 & 0.9647 & 3.4883 & 0.522587 \\
\hline & & Experimental & 0.8205 & 0.8007 & 0.427508 & 0.8205 & 0.8007 & 0.427508 & 0.8376 & 1.1733 & 0.549541 \\
\hline \multirow{10}{*}{$\begin{array}{c}\text { Dm } \\
\text { II }\end{array}$} & \multirow{5}{*}{$\begin{array}{l}0.5 \\
\mathrm{mg}\end{array}$} & Theoretical (no noise) & 0.3857 & 5.4284 & 0.000000 & 0.3857 & 5.4284 & 0.000000 & 0.3857 & 5.4284 & 0.000000 \\
\hline & & Noise $(K=0.1)$ & 0.3728 & 4.7845 & 0.236852 & 0.3728 & 4.7846 & 0.236853 & 0.3799 & 5.0522 & 0.630618 \\
\hline & & Noise $(K=0.2)$ & 0.3891 & 5.5285 & 0.431711 & 0.3892 & 5.5289 & 0.431693 & 0.4170 & 6.4317 & 1.059852 \\
\hline & & Noise $(K=0.5)$ & 0.4568 & 7.5943 & 0.952020 & 0.4568 & 7.5950 & 0.952121 & 0.5165 & 8.9171 & 2.272647 \\
\hline & & Experimental & 0.3857 & 5.4266 & 1.228060 & 0.3858 & 5.4296 & 1.227746 & 0.5990 & 10.2764 & 2.613943 \\
\hline & \multirow{5}{*}{$\begin{array}{c}5 \\
\text { mg }\end{array}$} & Theoretical (no noise) & 0.8205 & 0.8007 & 0.000000 & 0.8205 & 0.8007 & 0.000000 & 0.8205 & 0.8007 & 0.000000 \\
\hline & & Noise $(K=0.1)$ & 0.8201 & 0.8033 & 0.199059 & 0.8201 & 0.8034 & 0.199054 & 0.8228 & 0.8638 & 0.235111 \\
\hline & & Noise $(K=0.2)$ & 0.8219 & 0.8831 & 0.405815 & 0.8219 & 0.8834 & 0.405813 & 0.8356 & 1.1819 & 0.482324 \\
\hline & & Noise $(K=0.5)$ & 0.9526 & 3.2904 & 0.481151 & 0.9526 & 3.2905 & 0.481173 & 0.9647 & 3.4881 & 0.522568 \\
\hline & & Experimental & 0.8205 & 0.8006 & 0.427503 & 0.8205 & 0.8009 & 0.427530 & 0.8376 & 1.1728 & 0.549500 \\
\hline
\end{tabular}


A.

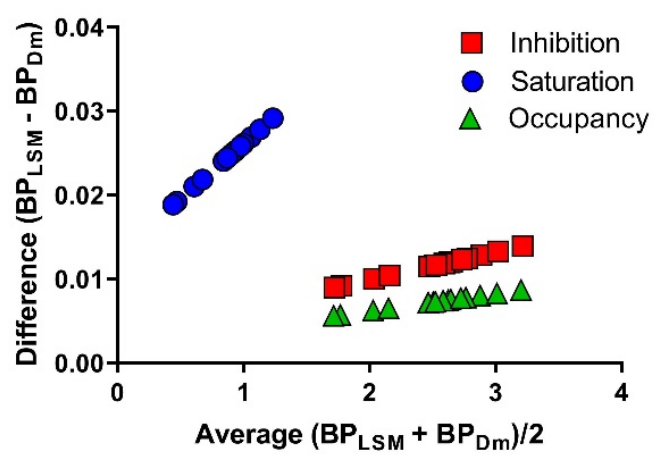

C.

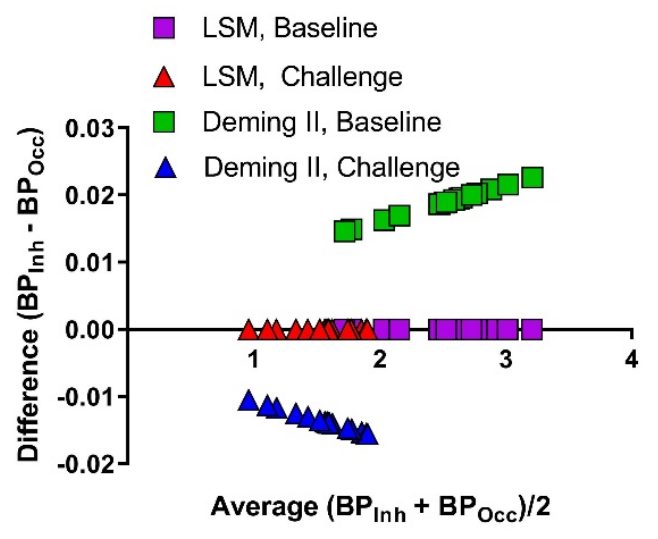

B.

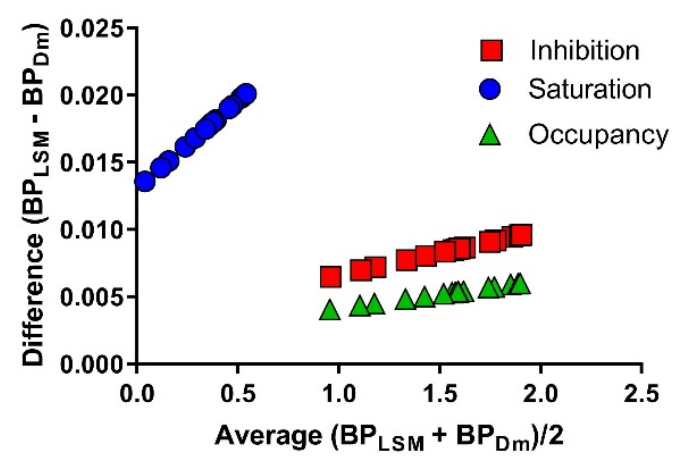

D.

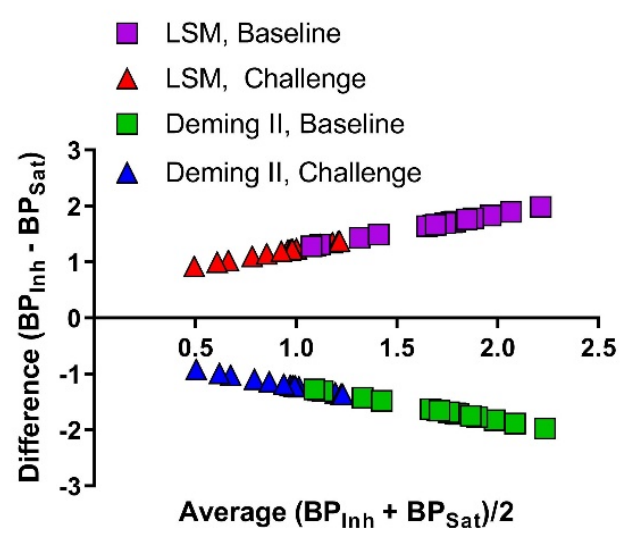

E.

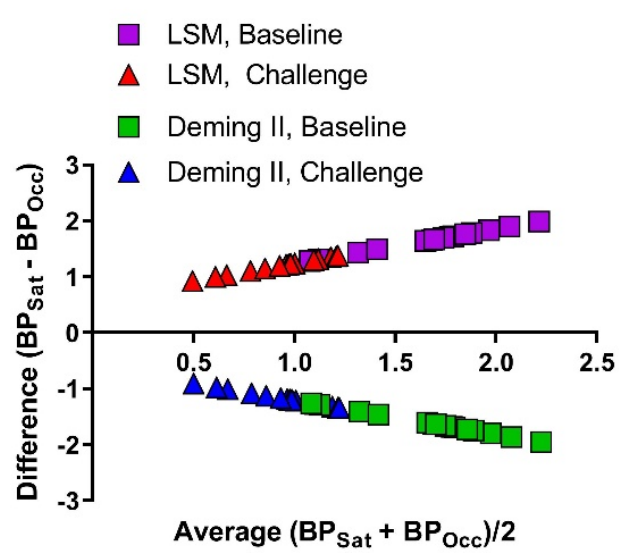

Supplemental Figure 1. Bland-Altman plots for binding potentials at $0.5 \mathrm{mg}$ DMXB-A inhibition by Horti et al. (17). Comparison of methods and plots, A. LSM vs. Dm at baseline. B. LSM vs. Dm at challenge. C. Inhibition vs. Occupancy. D. Inhibition vs. Saturation. E. Saturation vs. Occupancy 

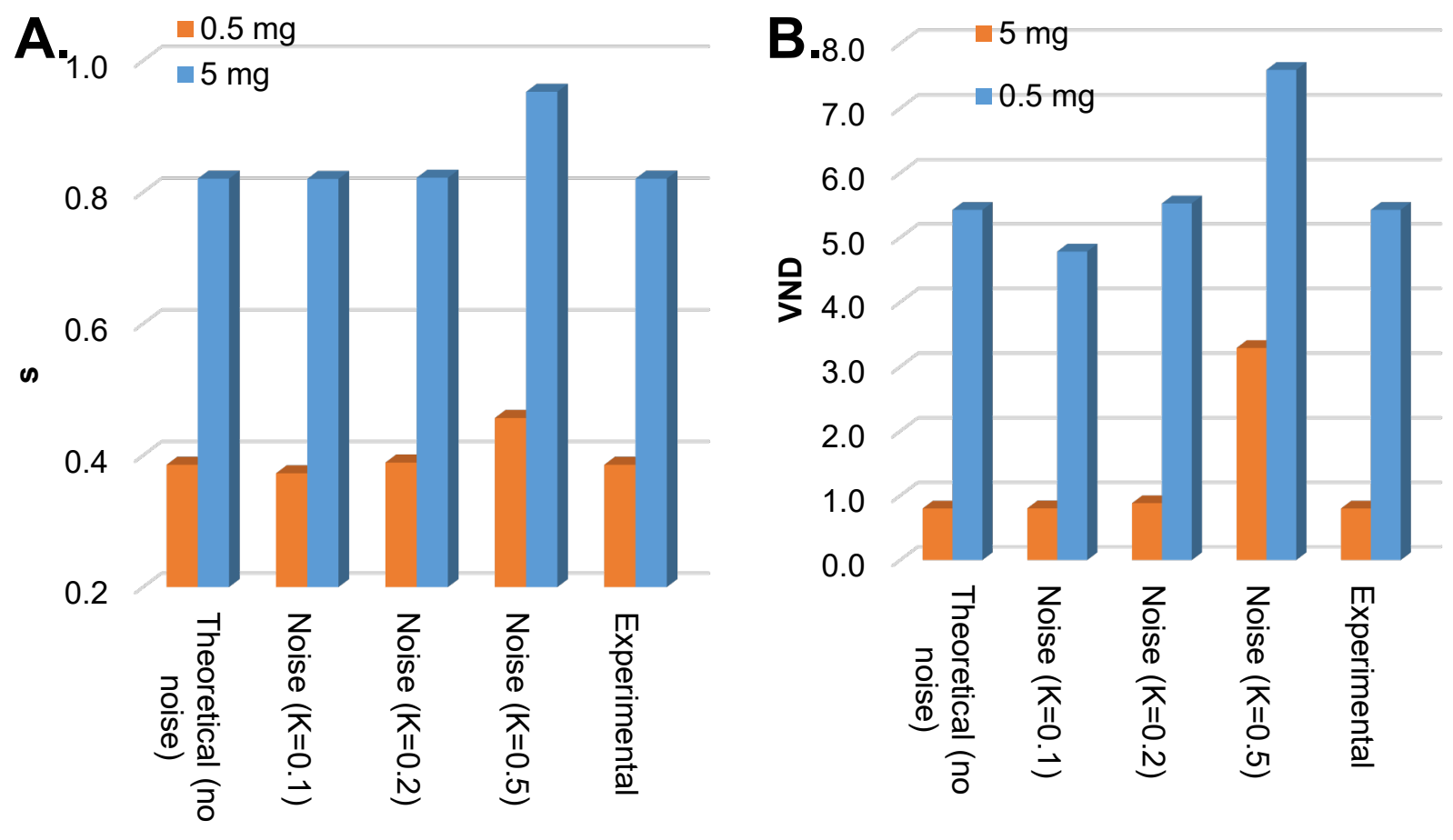

Supplemental Figure 2. Effect of noise on A. occupancy (s) and B. distribution volume of non-displaceable binding compartment $\left(V_{\mathrm{ND}}\right)$ by inhibition plot of LSM from Horti et al. (17) 

A.
- Theoretical (no noise)
noise $(\mathrm{K}=0.1)$
B.
- Theoretical (no noise)
Noise $(K=0.1)$
0.390
0.830
0.828

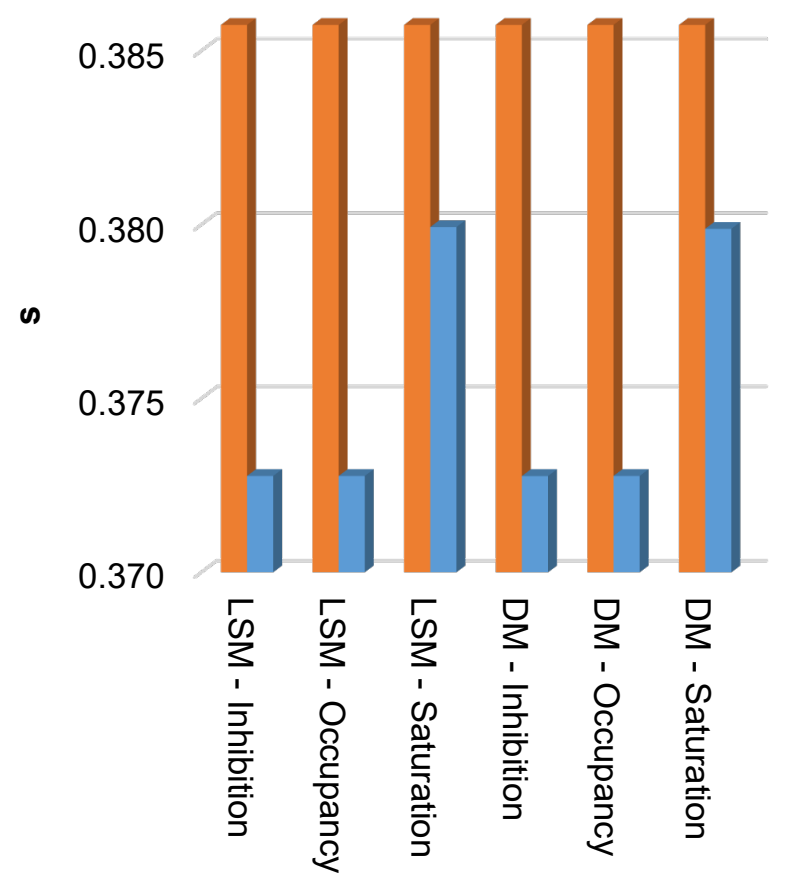
0.825

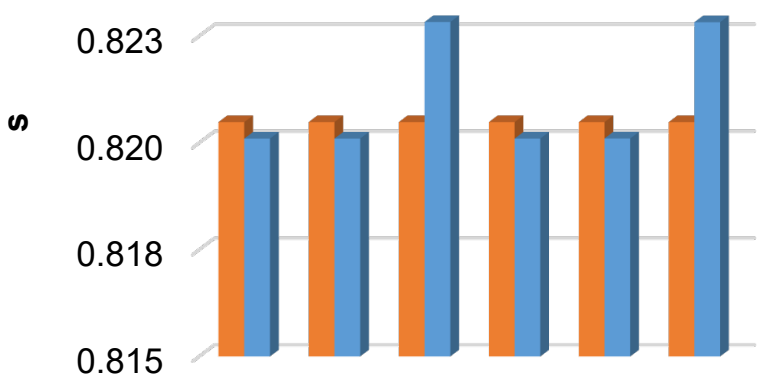

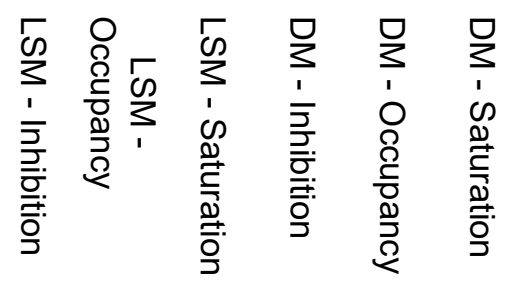

Supplemental Figure 3. Comparison of occupancy $(s)$ in different plots and linearizations with and without noise (A. $0.5 \mathrm{mg}$, B. $5 \mathrm{mg}$ ) from Horti et al. (17), Using data without noise, all three plots and two linearizations resulted exactly in the same parameter estimates. 


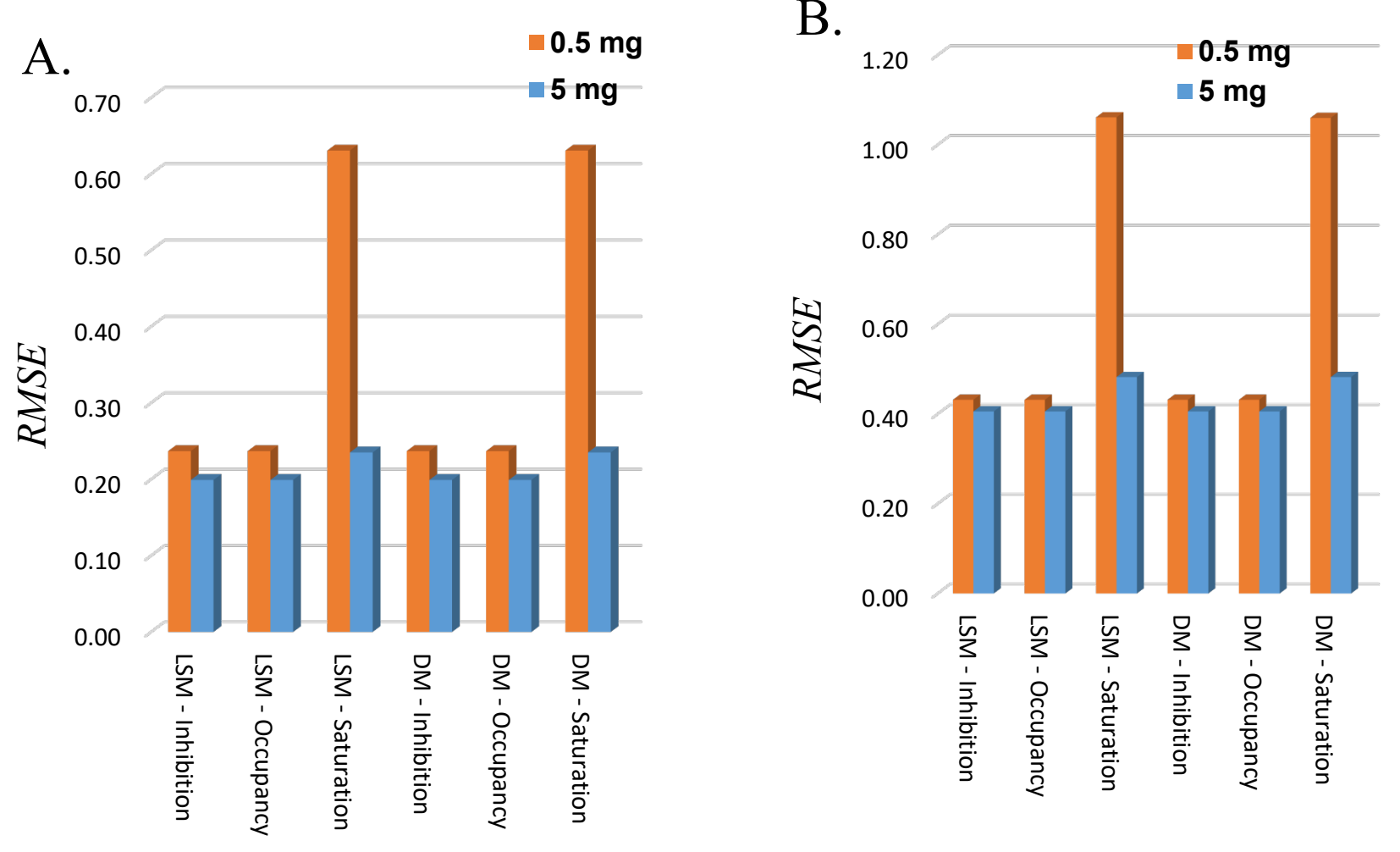

Supplemental Figure 4. Comparison of RMSE in three plots and two linearizations. A. noise at $\mathrm{K}=0.1, \mathrm{~B}$. noise at $\mathrm{K}=0.2$ for data from Horti et al. (17) 